\title{
TOWARDS BEST PRACTICES IN THE ENGINEER-TO-ORDER BUSINESS: A FRAMEWORK FOR THE STRUCTURED ANALYSIS OF COMMISSIONING PROCESSES
}

\author{
G. O. Mueller ${ }^{\otimes}$, C. A. Bertram and N. H. Mortensen \\ DTU-Technical University of Denmark, Denmark \\ $\triangle$ gemul@dtu.dk
}

\begin{abstract}
Engineer-To-Order (ETO) companies develop complex one-of-a-kind products based on specific customer demands. Given the product uniqueness, the commissioning plays an important role in the product development process. However, the project variety and low data availability hinder the analysis of the commissioning processes. This paper proposes a framework for the structured analysis of commissioning processes in ETO companies by analysing the impacts from product requirements and design on the commissioning performance. A case study presents the practical application of the developed framework.
\end{abstract}

Keywords: production design, complex systems, process improvement, ramp-up, engineer-to-order

\section{Introduction}

In the Engineer- To- Order (ETO) business a company designs and manufactures a new product based on specific customer requirements that demand a unique engineering design or significant customization of proven designs. ETO products are often highly complex, produced in low volume and developed in close collaboration with the customer. One example for ETO products are production systems such as processing plants (Joergensen et al., 2010). Given the uniqueness of each product, the commissioning, including the testing of sub-systems and the initial ramp-up to operation, is an increasingly significant part of the product development process (Haller et al., 2003). In order to evaluate the success of the product development project and to reveal best practices, it is therefore necessary to evaluate the relation between product design and commissioning (Langowitz, 1988).

The investigation of relationships between product development and commissioning in the ETO context proves to be difficult. Typical characteristics of ETO companies, such as the uniqueness of each developed product, a project-based organizational structure and a challenging information management, prevent companies from efficiently comparing product design and commissioning in order to improve future development projects (Foehr et al., 2015; Hobday, 2000).

In order to overcome these obstacles, this article proposes a framework for the structured analysis of the commissioning phase in product development processes. In section 2, the terminology used in the context of this article is introduced and existing approaches are discussed. In section 3, the developed framework is presented. Section 4 covers the application of the framework in a case study in collaboration with a company in the ETO business. The articles concludes with a discussion of the benefits and limitations of the proposed framework in section 5 and a conclusion in section 6 . 


\section{State of the art}

The purpose of this article is to propose a framework for the analysis of commissioning processes in the ETO context. The following section presents the definition of the terminology used in the context of this article and reviews existing methods that focus on the dependencies between product design and commissioning.

\subsection{Commissioning}

Literature regarding the commissioning and ramp-up of production systems shows inconsistencies in nomenclature and definition of the terms involved. Especially the terms commissioning, start-up and ramp-up are used differently across publications.

According to Tribe and Johnson (2008), the commissioning occurs prior to the start-up of the plant. The commissioning phases include safety, equipment checkout and various kinds of production runs. $\mathrm{Yu}$ and Wang (2010) define the phases of commissioning as preliminary test, function test and startup. In Wilhelm and Sastri (1979), start-up is defined as the process of starting the production in a newly built production system, while ramp-up refers to the introduction of a new product.

In general, the process of starting up is often referred to as ramp-up in literature, independent of whether it describes a new plant or the production of a new product in an existing production facility. Doltsinis et al. (2013) define ramp-up as a sequence of changes to the production system, with each of those adaptions changing the state of the system. In Terwiesch and Bohn (2001) and Schmitt et al. (2018), ramp-up is defined to start after completion of both product and process design with the overall aim of bringing the production system to full production capacity. In general, the objective of plant commissioning is to test and verify its operational reliability according to the requirements and intentions defined in the product development process ( $\mathrm{Yu}$ and Wang, 2010).

According to Haller et al. (2003), ramp-up also includes activities for the qualification and testing of the equipment, thereby overlapping with the aforementioned definition of commissioning.

Given the inconsistencies in literature, the terminology has to be defined. In the context of this publication, the commissioning is defined as the interface between the installation of the production system and its operation (see Figure 1). The commissioning process is divided into two sets of activities, qualification of sub-systems and ramp-up, which do not necessarily have to be carried out sequentially. The qualification aims to test and verify the state of the installed equipment, thereby ensuring its operational reliability. The objective of the ramp-up is to put the installed equipment into operation with the objective of achieving the pre-defined operational characteristics. In the case of commissioning of production systems, examples for those characteristics are production capacity and product quality.

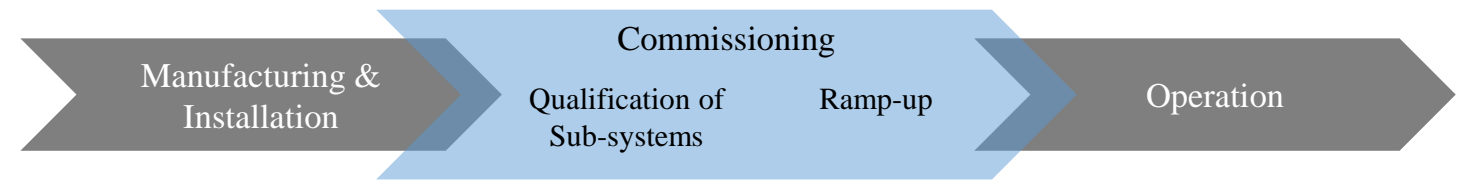

Figure 1. Commissioning

\subsection{Relation between commissioning and product development}

The importance of the commissioning process for the success of the product development project is agreed upon in literature. Hence, the improvement of commissioning and ramp-up has been the focus of many studies. Numerous studies focus on the investigation and improvement of knowledge management in the context of ramp-up (Doltsinis et al., 2018; Oates et al., 2012; Scrimieri et al., 2015). Others focus on improving the training of operators (Kampker et al., 2014a) or the estimation of ramp-up cost (Winkler and Slamanig, 2008). Most of the reviewed studies focus on discrete manufacturing and assembly industries. Kremsmayr et al. (2016) on the other hand introduces the application of agility principles in ramp-up management in process-oriented industries.

However, the mentioned methods disregard the impact of the design of the production system on the commissioning performance. The investigation of the dependence between the product design and the commissioning phase has been identified as a valuable path of research (Colledani et al., 2018; Surbier 
et al., 2014; Terwiesch and Bohn, 2001), but detailed investigations into that relation are scarce. Colledani and Yemane (2013) focus on the improvement of decisions made in the design of multistage manufacturing systems. Although the purpose of the study is to overcome data uncertainty, the proposed approach is heavily data-driven and therefore unfit to be applied in an environment characterized by a challenging information management such as ETO businesses. Basse et al. (2014) propose a generic approach for the design of scalable ramp-up processes, enabled by modularized manufacturing systems. The ramp-up process is designed based on experiences from an existing production line. Details on how to compare and analyse ramp-up process, given their one-of-a-kind character, is missing from the publication. Hence, the development of an approach to enable the comparison of existing production systems is necessary. Burggräf et al. (2016) follow a similar approach by proposing the development of standardized or modular factories. The benefits of standardized factories with regard to the ramp-up are discussed in detail. However, the publication is lacking an approach for the definition of standardized modules and processes that is applicable to companies.

The proposed framework developed and applied in the context of this study aims to overcome the presented shortcomings by enabling the structured comparison of the design of the production system and its implications on the commissioning process.

\section{Methodology}

The following section introduces the framework developed in this study. The general structure of the framework is presented and three kinds of insights that can be gained from the application of the framework are introduced.

\subsection{Overview of the developed framework}

The objective of the developed framework is to enable an analysis of commissioning structures used in past projects, the resulting performance and the impact from product requirements and product design. The overall goal of the framework application is to work towards the identification of best practices in ETO companies.

The developed framework is presented in Figure 2. The columns of the framework represent the respective product development projects and resulting products that are selected to be part of the analysis. It is necessary to ensure that the selected projects, despite their uniqueness and differences, show a certain degree of similarity and are therefore qualified for the comparison with the proposed framework. The presentation of the case study in section 4 gives an exemplary overview of the criteria applied in this study. Given the uniqueness of projects and the vast variety of industries and applications related to the ETO business, the criteria for project selection might differ with regard to the characteristics of the specific case.

The rows of the matrix represent the project characteristics for the investigation. The framework includes three characteristics for the product development project and two commissioning performance characteristics. Approaches for the modelling and visualization for all characteristics are presented in the context of the case study in section 4.

In order to use the framework for the analysis of commissioning processes, the commissioning structure is selected as one characteristic. Given the uniqueness of the products, the commissioning of the ETO product depends largely on its design. Therefore, the product structure is chosen as a second parameter for the analysis with the developed framework. In order to account for the significant dependency between product design and customer demands in the ETO business, the product requirements are used as a third characteristic.

Furthermore, two performance characteristics for the commissioning processes of the product development project are identified. Commissioning is a critical aspect to the success of the product development, being one of the most expensive processes in the project (Elstner and Krause, 2012; Glock and Grosse, 2015; Haller et al., 2003). Therefore, the cost of the commissioning process is included as one performance characteristic. In addition to the cost of commissioning, Kampker et al. (2014b) identify "time minimization" as one of the main objectives in commissioning optimization. The time aspect of the commissioning phase is therefore chosen as a second performance characteristic. 


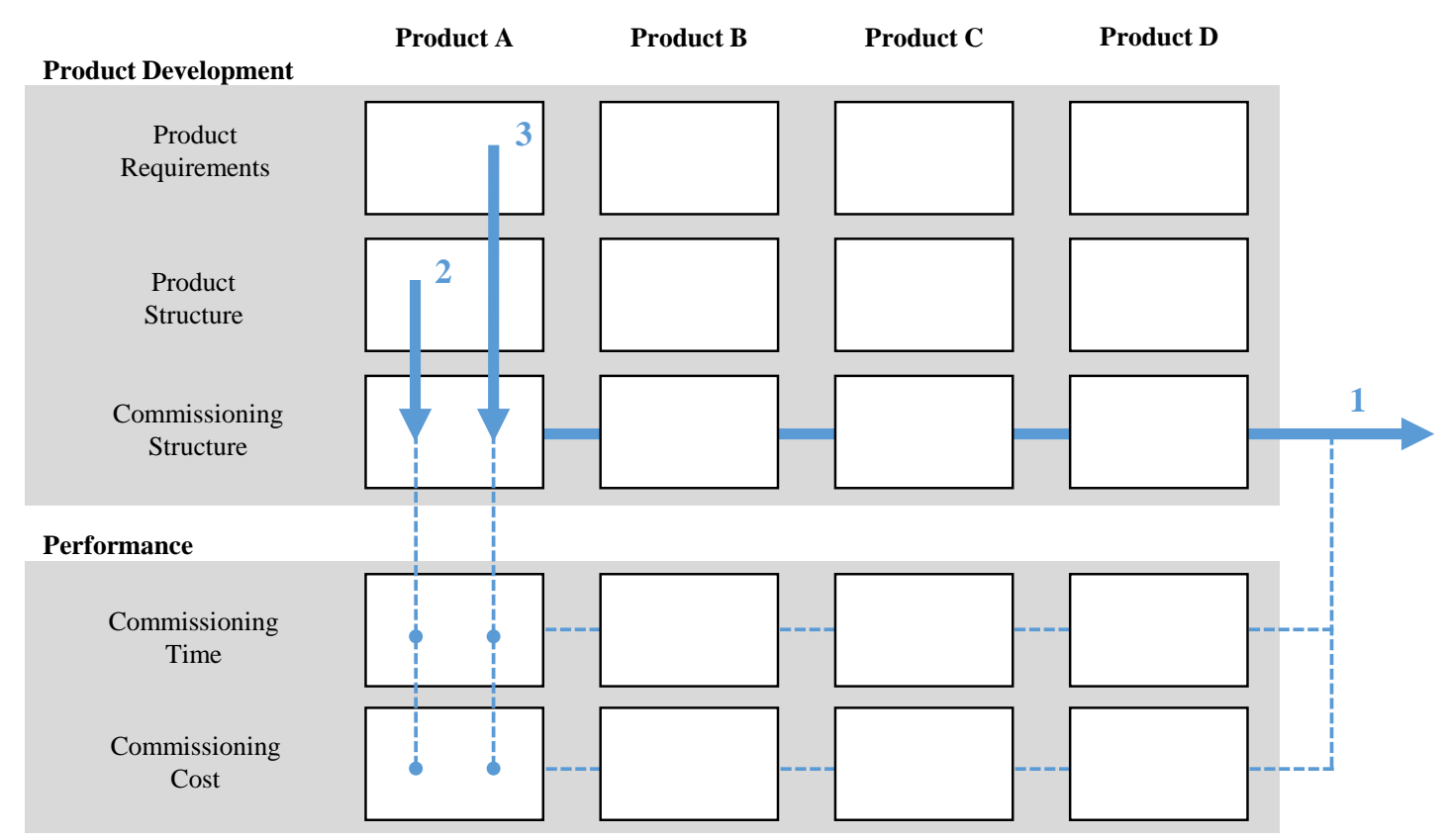

Figure 2. Framework and types of insights gained from its application

\subsection{Analysis of the commissioning process}

The application of the framework enables three kinds of insights. First, the commissioning structure can be compared across projects (see Figure 2 Insight 1). For example, it can be determined if certain activities are part of all commissioning structures and what impact those activities have on the performance of the commissioning process. The insights from that analysis can then be used to form the stable core of activities when defining the commissioning architecture or to reveal best practices.

The second insight gained from the analysis regards the impact of the product structure on the commissioning structure and commissioning performance (see Figure 2 Insight 2). Design choices and their impact on the structure of the commissioning process can be investigated as well as the consequences on the performance resulting from the decisions taken in the design process.

The third insight can be determined by analysing the impact of the product requirements on the commissioning structure and performance (see Figure 2 Insight 3). Specific requirements that lead to delays or cost overruns can be identified and used in order to improve future product development projects in general and commissioning processes in particular.

\section{Case study}

In order to investigate the feasibility of the proposed framework a case study is conducted. The case company is introduced and the selection criteria for the projects that are part of the framework application are presented. Furthermore, the application of the proposed framework and a preliminary result of the analysis are presented. Due to confidentiality, the number and extent of results shown in this publication are limited. Therefore, a fictional case is imagined to illustrate the results (see section 4.3.1).

\subsection{Case company}

The case company develops and builds complex one-of-a-kind production systems and their components for customers by following the ETO approach. Each customer order is managed as a product development project. The product requirements that result from specific customer demands are used as foundation for the design process. Business processes in the product development include sales, design and engineering, procurement, installation and commissioning. A successful commissioning leads to the handover of the production system to the customer, who will then be responsible for its operation. The product development process of a whole production system usually takes between two and five years between order signature and handover of the production system to the customer. 


\subsection{Project selection}

The first step of applying the proposed framework is to select the projects that should be in scope of the analysis. The following subsections present the selection criteria applied in the context of this study. Depending on the company and product, those selection criteria might have to be adapted to the specific use case.

Despite their uniqueness, the product development projects and respective products included in the analysis have to be similar to a certain degree. It is therefore recommended to only include products that belong to the same product family. In this study, expert interviews in the case company are conducted to identify the product family that is considered to be most significant to fulfil future customer demands as subject of the framework application.

Given the ETO approach, the scopes of the projects executed in the case company differ significantly, from designing single components for one customer to developing and erecting whole production systems for others. To ensure comparability of the projects, it needs to be ensured that all projects cover the same scope. In this study, only projects with the objective of developing and building whole production systems are included.

Technologies and customer demands evolve over time. It is therefore necessary to limit the range of projects to a certain period of time in order to ensure comparability. In this case study, the projects have been executed over a period of 11 years.

\subsection{Application of the developed framework}

The framework presented in section 3 is applied to the range of projects selected based on the criteria in section 4.2. The following subsections present the determination of each of the product development and performance characteristics described in section 3.1. Depending on the specific use case of the framework, different approaches might be undertaken in order to determine and visualize the characteristics. For the approaches chosen in this study the used documentation is listed and the visualization to illustrate the characteristic is selected. Furthermore, a fictional case is introduced to clarify the approach undertaken in the case study.

\subsubsection{Exemplary results}

Given the confidentiality of the case study, only generic case study results can be presented in this article. In order to support the reader in understanding the application of the framework and the methods developed in the context of the case study, a fictional ETO company "Heat Inc." is imagined. Heat Inc. produces customized district heating substations for multi-apartment buildings based on customer requirements. District heating substations connect to the general heat distribution network and realize the supply of heat and/or hot water to the apartments of the customer's building. In the following subsections, the results gained from the application of the developed framework to the case company are presented in generic form and expanded with the replication of the results for the fictional case of Heat Inc.

\subsubsection{Product requirements}

The product requirements for the development project are based on the customer demands. Contractual documentation such as tenders and orders are used to extract the product requirements for each product. Expert interviews with design experts in the case company are conducted to identify key requirements with influence on product design and/or commissioning execution to be included in the analysis.

A radar chart is chosen to visualize the product requirements that result from customer demands (see Figure 3.a). The axis scales of the radar chart do not necessarily have to be identical. However, in order to ensure comparability, it is necessary to have the same chart axes for all products in the scope of the analysis. For each product, the respective requirements are plotted onto the radar chart (see Figure 3.a). This provides an overview that is easy to comprehend and compare across projects.

Figure $3 \mathrm{~b}$ shows the product requirements for the fictional case of Heat Inc. Exemplary requirements for the development of a district heating substation could be the number of apartments that have to be supplied with heat and hot water, parameters such as pressure and temperature and customer's design demands like the tank capacity. 

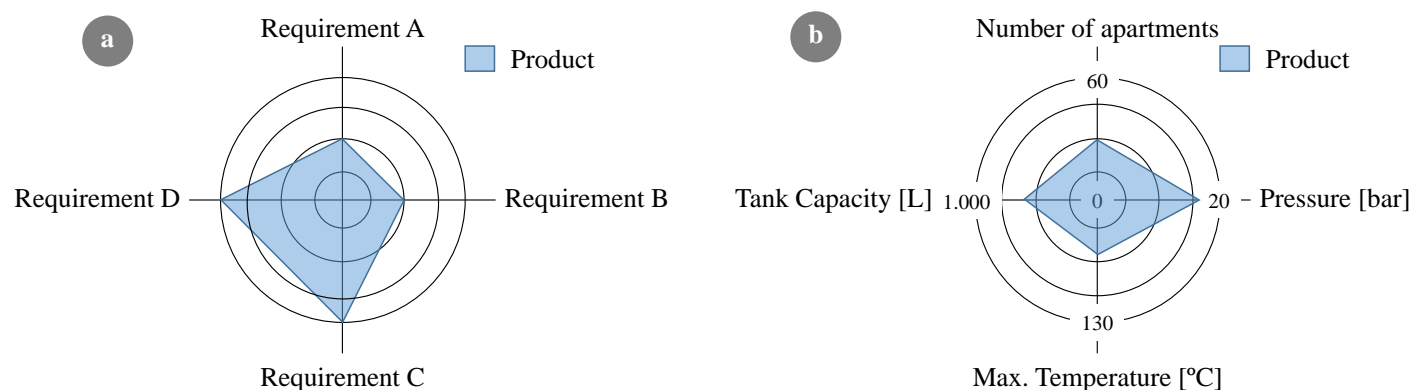

Max. Temperature $\left[{ }^{\circ} \mathrm{C}\right]$

Figure 3. Visualization of product requirements (a. Case study, b. Fictional result Heat Inc.)

\subsubsection{Product structure}

The product structure represents a decomposition of the physical subsystems and components that constitute the product. The objective of including this characteristic in the analysis is to identify similarities and differences in the product structure across products and their potential influence on the commissioning. As stated before, given the uniqueness of products in the ETO business a comparison of product composition is difficult. Nevertheless, when following the criteria for project selection described in section 4.2, the comparison of the product structure on a high level is possible. Therefore, only the main components of the product are included in this study. The identification of the key components or subsystem is executed based on the insights from expert interviews with designers and project managers in the case company. Furthermore, one level of detail can be added to the analysis by including the main sizes of each component in the product structure. In this case study, the product structure is determined based on process calculations and technical drawings of components.

The product structure is visualized as shown in Figure 4.a. In this graph, each block represents a main component. Interfaces between the components are visualized with a line. In cases where the direction of the interface is important, arrows can be used instead of lines. The main sizes of the components can be added to each block to enrich the analysis.
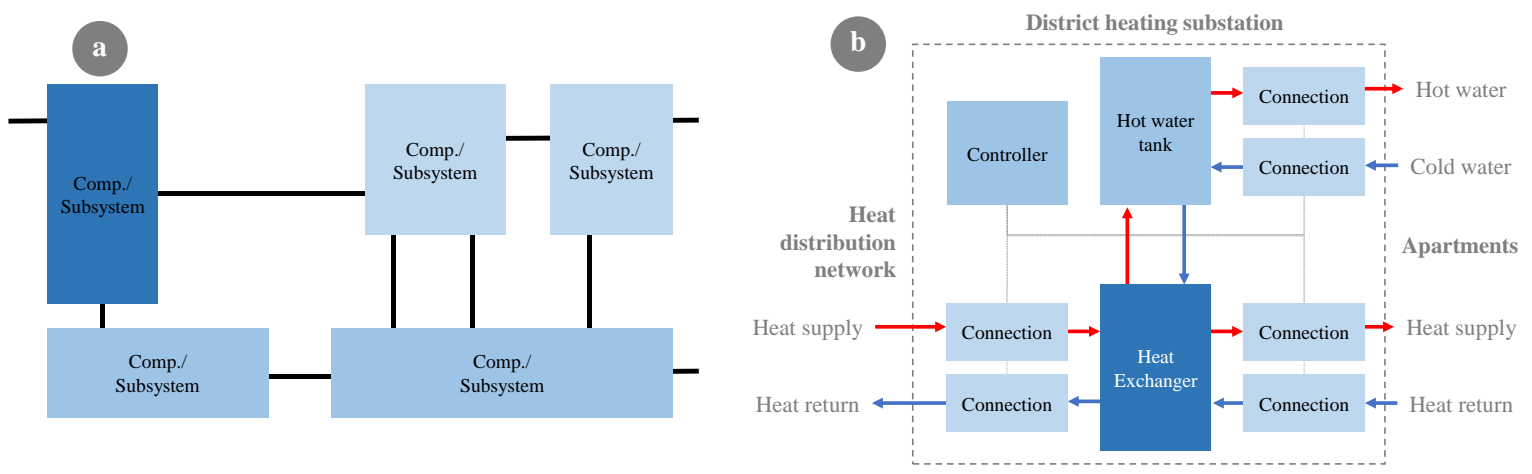

Figure 4. Visualization of product structure (a. Case study, b. Fictional result Heat Inc.)

A fictional example for the product structure of a district heating substation designed by Heat Inc. based on the customer requirements presented above is shown in Figure 4.b. The arrows between the blocks represent the flow of hot and cold water between the components. Furthermore, the flow between the product and its environment, namely the heat distribution network on the left side of the product and the apartments to the right, is visualized. The electrical interfaces between the controller and the connection subsystems, including valves and pumps, are represented as well.

\subsubsection{Commissioning structure}

The commissioning structure represents a decomposition of the activities and tasks that have to be carried out in order to bring the production system into operation. Since the commissioning is highly dependent on the product design, unique products lead to unique commissioning processes. A comparison of commissioning structures across projects is therefore difficult. However, the underlying principle is comparable on a high level if the projects are selected carefully as described in section 4.2. 
In this case study, two dimensions of the commissioning process are taken into account: its scope and the activities that are carried out. The scope describes what aspects of the commissioning process are mentioned in the planning documentation. Examples for those aspects are conditions for the start of commissioning, different testing sequences, product sequences and operator training. Furthermore, the level of detail for each of these aspects is noted to investigate what scope the focus of the commissioning project is on. One example for levels of detail can be: the commissioning documentation mentions "testing of components" (low level of detail) or it mentions the different tests for different components individually (high level of detail). In addition to the scope, the activities that are carried out during the commissioning process are listed. Depending on the level of detail in the data, the duration of each activity can be included to enrich the analysis. The information necessary to get an overview of scope and activities is taken from commissioning and planning documentation.

The visualization shown in Figure 5.a is chosen in order to illustrate the commissioning structure with the two dimensions presented above. It consists of two lists, describing the scope and activities respectively.

Figure 5.b shows a fictional example for the commissioning structure of one district heating substation designed by Heat Inc. The activities listed in the commissioning plans for the specific product are marked and their estimated durations are noted. The aspects of "Testing utilities", "Heat testing" and "Hot water testing" are not part of the commissioning documentation for this specific product despite their relevance for other products in the scope of the framework application and therefore not coloured in Figure 5.b.
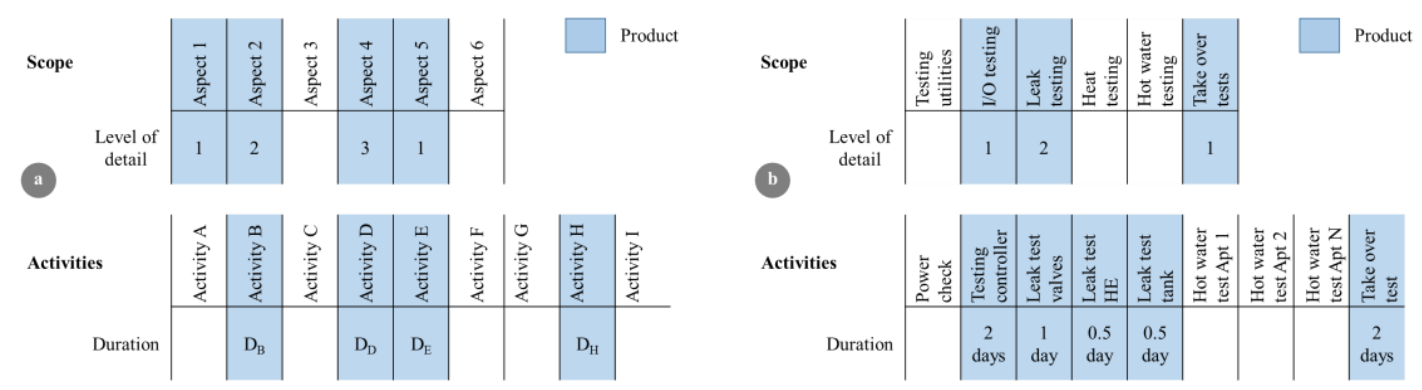

Figure 5. Visualization of commissioning structure (a. Case study, b. Fictional result Heat Inc.)

\subsubsection{Commissioning time}

In order to analyse the performance of the commissioning process in regards to time, both the estimated and actual commissioning duration have to be taken into account. The originally estimated commissioning duration is extracted from orders, the actual duration is based on planning documentation. Depending on the level of detail in the gathered data, the total commissioning duration can be divided into components. One example is the split of the commissioning process into qualification of subsystems and ramp-up as defined in section 2 (see Figure 1).

In order to visualize the time aspect of the commissioning phase, a stacked bar chart is chosen (see Figure 6.a). The initial delay of the start of the commissioning phase is calculated as the difference between actual and estimated start of commissioning. The final delay is calculated using the end of commissioning respectively. In order to simplify readability, the horizontal axis of the graph should be scaled identically for all projects in the scope of the analysis.
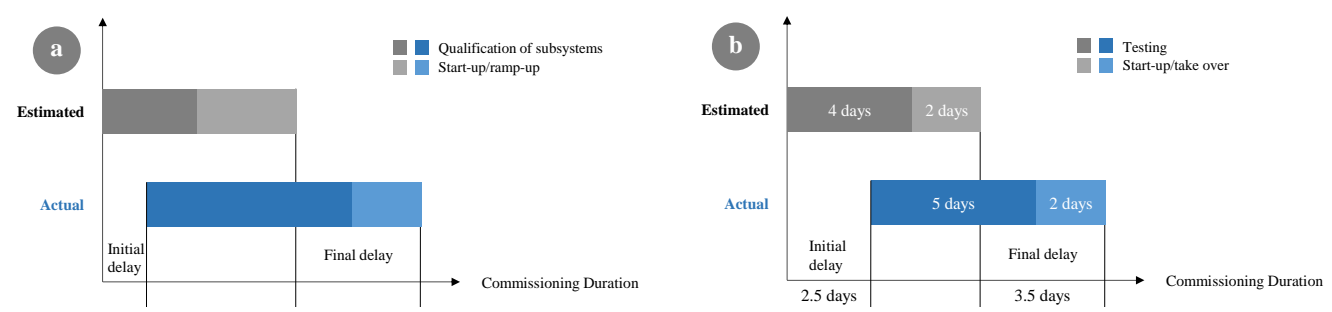

Figure 6. Visualization of commissioning time (a. Case study, b. Fictional result Heat Inc.) 
Figure 6.b shows the corresponding visualization of the commissioning time for the district heating substation developed by Heat Inc. based on the fictional results presented in the previous section. An initial delay of 2.5 days is added to the estimated commissioning time, as well as a delay of 1 day for the testing of components and subsystems, resulting in a 3.5 days final delay.

\subsubsection{Commissioning cost}

The evaluation of the performance of the commissioning process in regard to cost requires the consideration of both estimated and actual cost. The relevant data is gathered from cost estimations, budgets and employee hour registrations. In this study, expert interviews are conducted in order to identify the different aspects that influence the commissioning cost. Furthermore, a process analysis based on historical company data is carried out. Two main dimensions are identified to describe the impact each cost factor has on the overall commissioning cost: Location and responsible party. Each of these dimensions can be characterized in two ways (see Figure 7). Each cost unit with impact on commissioning can therefore be classified in one of four categories. The total commissioning cost calculates as the sum of the four cost categories.

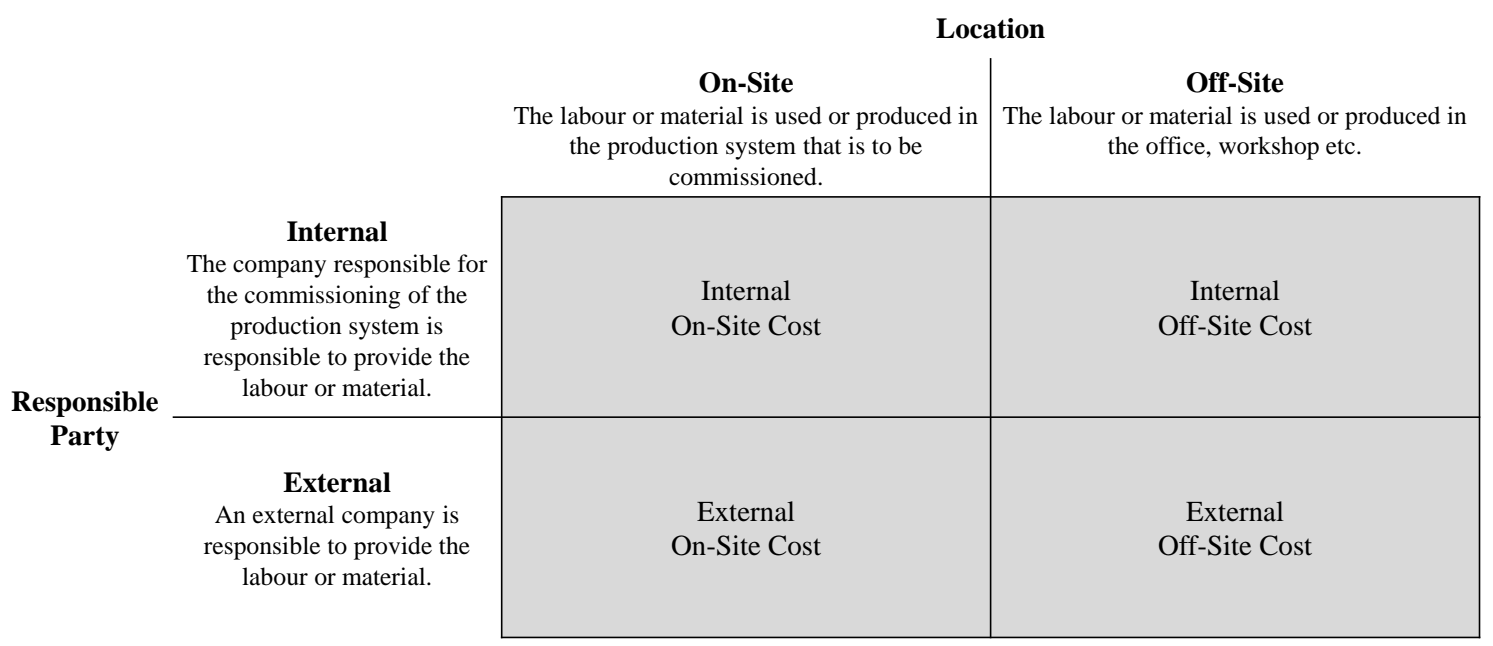

Figure 7. Decomposition of commissioning cost

The financial performance of the commissioning is visualized with a stacked bar chart (see Figure 8.a). The scale of the horizontal axis should be normalized across products in the analysis in order to simplify readability. In regard to the commissioning of the fictional district heating substation produced by Heat Inc., the described delays lead to increased internal off-site cost and external onsite cost (see Figure 8.b). Due to the nature of the fictional case, no external off-site cost occur.
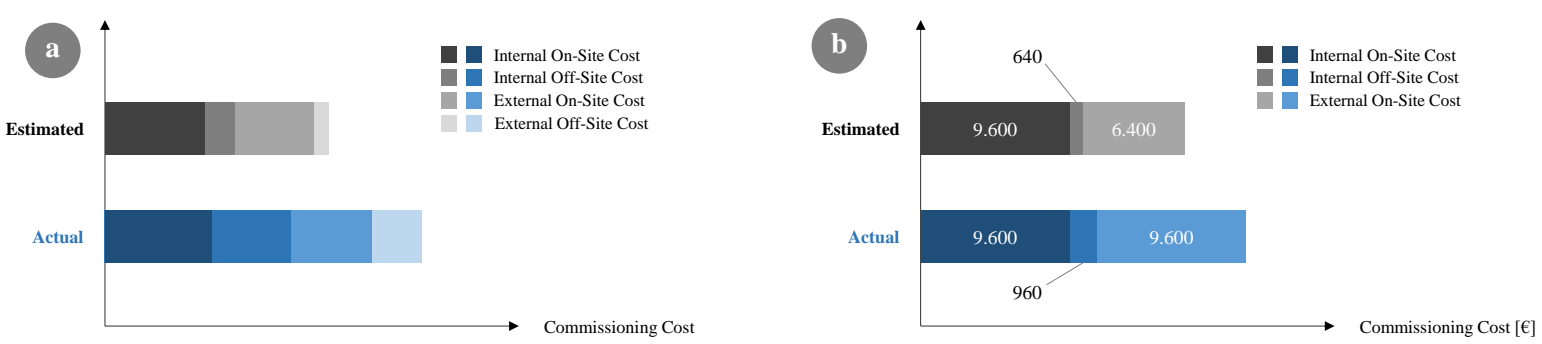

Figure 8. Visualization of commissioning cost (a. Case study, b. Fictional result Heat Inc.)

\subsection{Preliminary result}

The framework has been applied in collaboration with the case company as described in the previous sections. Due to confidentiality, the amount of results presented in this section is limited and no details can be disclosed. Nevertheless, this section presents an exemplary result from the preliminary analysis in the case company, demonstrating what can be expected when applying the developed framework. 
The high-level commissioning structure is analysed across multiple projects (see Figure 2 Insight 1). It is determined that certain commissioning activities are part of all commissioning processes in the scope of the analysis. This indicates that these activities are essential to any commissioning project in that product family. Furthermore, it can be seen that some activities only occur if the product structure includes certain components. This indicates that the proposed framework can be used to classify commissioning activities.

\section{Discussion}

The feasibility of the framework application in the ETO context has been indicated with the conduction of the case study. The study demonstrates that commissioning processes can be compared on a high level despite the uniqueness of products and processes across ETO projects. The identification of patterns across projects reveals the impact of product requirements and design decisions on the commissioning of the product and its performance. Furthermore, the visual character of the framework enables an uncomplicated communication of the identified patterns to practitioners. Nevertheless, the case study shows that the benefits gained from the framework application depend largely on the available data. The value of the insights gained from the analysis is linked to the level of detail in the data. Hence, in order to mitigate poor data quality and data unavailability that is typical for the ETO business (Hobday, 2000), the collection and structuring of the data necessary to perform an analysis such as the approach presented in this paper has to be further investigated.

\section{Conclusion}

Due to the uniqueness of products and product development projects in the Engineer-To-Order (ETO) business, companies often face difficulties when comparing products and projects in order to identify best practices. This article proposes a framework for the analysis of the commissioning process in the ETO business. The framework aims to analyse the structure of commissioning processes across complex one-of-a-kind products. The evaluation of the commissioning process is enabled by including the product requirements, product design and two performance characteristics in the framework.

A case study was conducted in collaboration with a company from the ETO industry. The case study shows the feasibility of the application of the framework in the ETO context. The application of the framework supports ETO companies in analysing historical product and project data and thereby identifying potential future improvements in regard to product and process design.

\section{References}

Basse, I., Sauer, A. and Schmitt, R. (2014), "Scalable ramp-up of hybrid manufacturing systems", Procedia CIRP, Vol. 20, Elsevier B.V., pp. 1-6. http://doi.org/10.1016/j.procir.2014.05.024

Burggräf, P., Dannapfel, M. and Voet, H. (2016), "Potentials of Factory Standards in Production Ramp-Ups", Procedia CIRP, Vol. 51, The Author(s), pp. 134-139. http://doi.org/10.1016/j.procir.2016.06.088

Colledani, M., Tolio, T. and Yemane, A. (2018), "Production quality improvement during manufacturing systems ramp-up”, CIRP Journal of Manufacturing Science and Technology, CIRP, Vol. 23, pp. 197-206. http://doi.org/10.1016/j.cirpj.2018.07.001

Colledani, M. and Yemane, A. (2013), "Impact of machine reliability data uncertainty on the design and operation of manufacturing systems", Procedia CIRP, Vol. 7, Elsevier B.V., pp. 557-562. http://doi.org/ 10.1016/j.procir.2013.06.032

Doltsinis, S., Ferreira, P. and Lohse, N. (2018), “A symbiotic human-machine learning approach for production ramp-up", IEEE Transactions on Human-Machine Systems, IEEE, Vol. 48 No. 3, pp. 229-240. http://doi.org/10.1109/THMS.2017.2717885

Doltsinis, S.C., Ratchev, S. and Lohse, N. (2013), "A framework for performance measurement during production ramp-up of assembly stations", European Journal of Operational Research, Vol. 229 No. 1, Elsevier B.V., pp. 85-94. http://doi.org/10.1016/j.ejor.2013.02.051

Elstner, S. and Krause, D. (2012), "Towards an early consideration of ramp-up phase in the product development of complex products", Proceedings of International Design Conference, DESIGN, Vol. DS 70, pp. 859-868.

Foehr, M., Gepp, M. and Vollmar, J. (2015), "Challenges of system integration in the engineer-to- order business", IECON 2015 - 41st Annual Conference of the IEEE Industrial Electronics Society, IEEE, pp. 7379. http://doi.org/10.1109/IECON.2015.7392078 
Glock, C.H. and Grosse, E.H. (2015), "Decision support models for production ramp-up: A systematic literature review", International Journal of Production Research, Vol. 53 No. 21, Taylor \& Francis, pp. 6637-6651. http://doi.org/10.1080/00207543.2015.1064185

Haller, M., Peikert, A. and Thoma, J. (2003), "Cycle time management during production ramp-up", Robotics and Computer-Integrated Manufacturing, Vol. 19 No. 1-2, pp. 183-188. http://doi.org/10.1016/S07365845(02)00078-9

Hobday, M. (2000), "The project-based organisation: An ideal form for managing complex products and systems?”, Research Policy, Vol. 29 No. 7-8, pp. 871-893. http://doi.org/10.1016/s0048-7333(00)00110-4

Joergensen, S.N., Nielsen, K. and Joergensen, K.A. (2010), "Reconfigurable manufacturing systems as an application of mass customisation", International Journal of Industrial Engineering and Management, Vol. 1 No. 3, pp. 111-119.

Kampker, A. et al. (2014a), "Increasing ramp-up performance by implementing the gamification approach", Procedia Cirp, Vol. 20 No. C, pp. 74-80. https://doi.org/10.1016/j.procir.2014.05.034

Kampker, A., Deutskens, C. and Maue, A. (2014b), "Development of a methodology for cost-oriented ramp-up design", IEEE International Conference on Industrial Engineering and Engineering Management, Vol. 2015-Janua, IEEE, pp. 998-1002. http://doi.org/10.1109/IEEM.2014.7058788

Kremsmayr, M. et al. (2016), "On the Application of Agility Principles in Ramp-up Management: Approaching the Challenges in the High-end Powder Metallurgy Industry", Procedia CIRP, Vol. 51, pp. 85-92. http://doi.org/10.1016/j.procir.2016.05.045

Langowitz, N.S. (1988), "An exploration of production problems in the initial commercial manufacture of products", Research Policy, Vol. 17 No. 1, pp. 43-54.

Oates, R., Scrimieri, D. and Ratchev, S. (2012), "Accelerated Ramp-Up of Assembly Systems through Selflearning”, 6th International Precision Assembly Seminar (IPAS), Vol. 21, pp. 175-182. https://doi.org/10. 1007/978-3-642-28163-1

Schmitt, R. et al. (2018), “On the future of ramp-up management”, CIRP Journal of Manufacturing Science and Technology, CIRP, Vol. 23, pp. 217-225. http://doi.org/10.1016/j.cirpj.2018.03.001

Scrimieri, D., Oates, R.F. and Ratchev, S.M. (2015), "Learning and reuse of engineering ramp-up strategies for modular assembly systems", Journal of Intelligent Manufacturing, Vol. 26 No. 6, Springer US, pp. 10631076. http://doi.org/10.1007/s10845-013-0839-6

Surbier, L., Alpan, G. and Blanco, E. (2014), “A comparative study on production ramp-up: State-of-the-art and new challenges", Production Planning and Control, Vol. 25 No. 15, Taylor \& Francis, pp. 1264-1286. http://doi.org/10.1080/09537287.2013.817624

Terwiesch, C. and E. Bohn, R. (2001), "Learning and process improvement during production ramp-up", International Journal of Production Economics, Vol. 70 No. 1, pp. 1-19. http://doi.org/10.1016/S09255273(00)00045-1

Tribe, M.G. and Johnson, R.R. (2008), "Effective capital project commissioning", IEEE Conference Record of Annual Pulp and Paper Industry Technical Conference, pp. 106-119. http://doi.org/10.1109/PAPCON.2008.4585812

Wilhelm, W.E. and Sastri, T. (1979), "An investigation of flow line operating characteristics during start-up", International Journal of Production Research, Vol. 17 No. 4, pp. 345-358. https://doi.org/10.1080/ 00207547908919619

Winkler, H. and Slamanig, M. (2008), "Konzeption eines aktivitätsorientierten Instruments zur Anlaufkosten planung", Zeitschrift Fur Planung Und Unternehmenssteuerung, Vol. 19 No. 1, pp. 85-106. http://doi.org/ 10.1007/s00187-008-0043-6

Yu, Y. and Wang, C. (2010), "Management and practice of CPR1000 nuclear power plants commissioning and startup”, International Conference on Nuclear Engineering, Proceedings, ICONE, Vol. 1, pp. 1-5. http://doi.org/10.1115/ICONE18-30150 